\title{
English in Eastern Ethiopia is Learnt; Not Mastered
}

\author{
Sanjay Kumar Jha ${ }^{1}$ \\ ${ }^{1}$ Department of English, Haramaya University, Ethiopia \\ Correspondence: Dr. Sanjay Kumar Jha (Associate Professor), P. Box \# 335, Haramaya University, Ethiopia. \\ Permanent address: O-1/34, Budh Vihar, Delhi-86, India. Tel: 251-923-203-251. E-mail: brimedian@gmail.com
}

Received: January 10, 2013 Accepted: February 27, 2013 Online Published: March 10, 2013

doi:10.5539/elt.v6n4p42 URL: http://dx.doi.org/10.5539/elt.v6n4p42

\begin{abstract}
English Language Teaching (ELT) has undergone immense changes over the years in terms of using different methods, but none of the methods till this date have proved what they had proclaimed. The paper believes in the hypothesis that learning is understanding the linguistic components of a language, whereas mastering is the part of using them in a well structured way with perfection and ease. Viewing this dichotomy between learning and mastering, the paper examines a problematic discourse: English in Eastern Ethiopia is often learnt; but not mastered. The broad concern of the paper is to draw the attention of the local and global ELT practitioners towards the dismal state of English in Eastern Ethiopia. In this pursuit, the paper set three prime objectives: (i) exploring global and local uses of ELT methods, (ii) exploring major linguistic and non-linguistic impediments in mastering English, and (iii) proposing an empirical approach to overcome the impediments from remedial perspective. Participant observation, unstructured Interview, and document analysis were employed to gather the data, whereas analytic induction was used to analyze the data. Under findings, seventeen linguistic and non-linguistic impediments were found as serious deterrents in mastering English. From remedial perspective, the paper proposes an empirical Integrated Iconic Approach to overcome the linguistic impediments followed by seventeen apposite recommendations to pave the path of quality English education in Eastern Ethiopia.
\end{abstract}

Keywords: learning, mastering, ELT (English Language Teaching), ELT methods, ELT activities, English

\section{Introduction}

Today, it goes without saying that English has not only become a lingua franca for us globally, but more importantly it has become a language of progress or a key to success in every walk of life. In Ethiopian context, English is being used paradoxically as a foreign language rather than second language because average Ethiopians believe that English can never be a crutch to survive in Ethiopian society. In 1994, a constitutional amendment was made in which regional languages were allowed to be used as the medium of instruction in Ethiopia. Although Ethiopia's need for English language is more intensified as globalization is the agenda of the time, the 'depressing picture of English language teaching' never improved (Eshetie, 2010). English is foreign to most, and is known and used only by a small minority of educated, economic, and/or political elite in Ethiopia (Bogale, 2009). There is a grave concern among the EFL learners in the eastern Ethiopia that they have been learning English for several years but they are not able to master it.

Viewing the concern of the learners, the paper believes in the hypothesis that learning is understanding the linguistic components of a language and mastering is the part of using them in a well structured way with perfection and ease. If learning is process, mastering is product; if learning is path, mastering is destination. Mastering is aimed at acquiring utmost perfection in speech fluency, writing accuracy, stylistic nuances, word choice, accent, etc. Despite acquiring linguistic competence, the learners find it difficult to make their competence functional in real life situation for lack of mastering the language as illustrated in Figure 1.

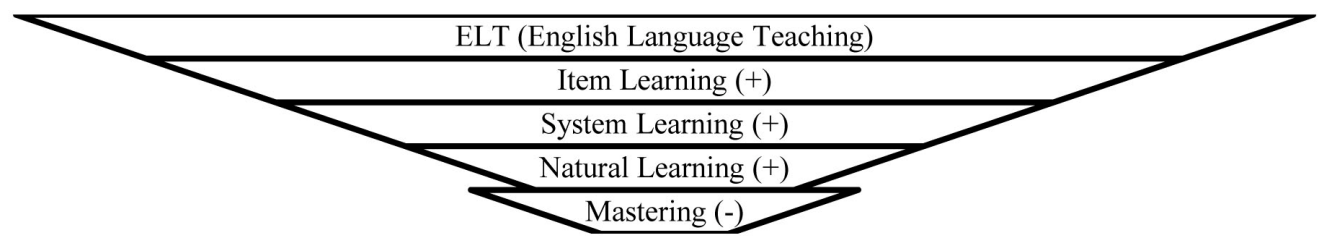

Figure 1. Learning vs. Mastering 
Figure 1 shows the shrinking layers of item learning, system learning, natural learning, and mastering respectively. Item learning refers to learning a language at word level; system learning refers to learning at sentence level; natural learning refers to the state in which learner starts learning a language either inductively or deductively using generalization, under-generalization, and over-generalization (Krashen, 1987). It is noteworthy that item, system, and natural learning occur in the Ethiopian classrooms, but mastering does not occur as marked with (+) and (-) respectively. The negative state of mastering was also determined through a brief piloting of the occurrence of learning and mastering four vital components and skills as shown in table 1.

Table 1. Occurrence of Learning and Mastering

\begin{tabular}{|l|l|l|l|l|l|l|l|l|}
\cline { 2 - 9 } \multicolumn{1}{c|}{} & \multicolumn{4}{l}{ COMPONENTS } & \multicolumn{2}{l|}{ SKILLS } \\
\cline { 2 - 10 } \multicolumn{1}{c|}{} & Vocabulary & Grammar & Structures & Accent & Listening & Speaking & Reading & Writing \\
\hline Learning & + & + & + & $+/-$ & $+/-$ & $+/-$ & + & $+/-$ \\
\hline Mastering & - & - & - & - & - & - & - & - \\
\hline
\end{tabular}

Though, learning occurs either positively $(+)$, negatively $(-)$, or in a mixed state $(+/-)$, there is no occurrence of mastering for the concerned components and skills in table 1. Given the negative state of mastering, the paper raises three research questions from causal and remedial perspectives.

\section{Research Questions and Objectives}

1) Is English being taught methodically in Ethiopia?

2) Why the learners cannot move on from learning to mastering phase?

3) How to devise an empirical approach to overcome linguistic impediments faced by the learners?

Conforming to the research questions, the paper limits its scope by setting three objectives as follows.

1) To carry out a comparative study of global and local uses of ELT methods.

2) To explore linguistic and non-linguistic impediments inside and outside EFL classrooms.

3) To propose an empirical approach to overcome linguistic impediments.

As for the significance of this study, the paper has pioneered a new area of discussion by addressing the learners' suppressed and accumulated outburst of not mastering English timely. Although a host of local researchers like Bogale (2009), Jeylon (2010), Eshetie (2010), and many others have discussed ELT issues from assessment, syllabus design, language planning, and gender perspectives, there is almost no local research concerned with exploring and rectifying the impediments in mastering English. Most of the local researchers often perceive and investigate ELT issues in terms of what rather than why, whereas the present work discusses the issues from causal as well as remedial perspectives.

\section{Research Methodology}

Viewing the exploratory nature of the problematic discourse that is 'why English in Eastern Ethiopia is often learnt; but not mastered', the research used ethnographic and phenomenological approaches. Ethnographic, in that it requires long-term observations and investigations of the participants mostly from emic perspective in which a group of ESL learners' own learning experience is investigated and partly from etic perspective in which researchers interpret what they see largely from their own perspective in order to validate the findings. Phenomenological, in that the present work is more oriented towards eliciting perceptions, beliefs, and feelings of the participants with emphasis on subjectivity rather than objectivity, interpretation rather than measurement.

\subsection{Participants and Sampling}

The participants of the study were 25 undergraduate and postgraduate students and 15 TEFL instructors of Haramaya, Dire Dawa, Jijiga Universities, and Harar secondary school. The participants were selected using purposive sampling as they were expected to have unique ability to explain, understand, and yield information about the problematic discourse.

\subsection{Data Collection}

Three data gathering instruments: participant observation, unstructured interview, and document analysis were employed to elicit the data. Participant observation, which enables researchers to assess what their subjects 
actually do, rather than what they say they do (Bloor \& Wood, 2006), allowed the researcher to directly immerse himself with the participants in 6 EFL classrooms to assess primarily the use and effectiveness of ELT methods and activities. Secondarily, it also observed the conformity between levels of the learners and ELT activities, contents of authentic materials, and impact of formative and summative assessment. Participant observation served the purpose of attaining the first research objective, whereas unstructured interview was used to attain the second research objective as it allows the respondents to answer freely and the researcher to probe and explore the exact and related problem(s) as they come up during the interview. As a part of document analysis, localized research papers were studied not only to triangulate the data and findings drawn from participant observation and unstructured interviews, but more importantly to enhance the credibility of the data. For instance, the reflections of 265 Haramaya University students in an ethnographic research by Jeylan (2010), underpinned the major findings of this research.

\subsection{Data Analysis}

Viewing the phenomenological nature of this research, Analytic Induction was deemed to be more apt for analyzing the data as it is a way to develop causal explanations of a phenomenon to accurately present the reality of the situation being studied. Since the focal concern of the research was to explore the impediments in mastering English, all the collected data (observed, heard, and read) were classified into thematic categories and interpreted based on the degree of emphasis and relativity of the participants' views.

\section{Findings and Discussion}

This section discusses the findings of (i) major ELT methods used globally and locally, (ii) the major linguistic and non-linguistic impediments in mastering English, and (iii) the proposal of Integrated Iconic Approach.

\subsection{Methods of ELT Used Globally}

The following are the brief accounts of 16 ELT methods with their theoretical base, focal skill(s), and activities.

Table 2. Methods of ELT used globally

\begin{tabular}{|c|c|c|c|}
\hline ELT Methods & Theoretical Base & Skill(s) & ities \\
\hline $\begin{array}{l}\text { Grammar } \\
\text { Translation } \\
\text { Method (GTM), } \\
1850 \text { s }\end{array}$ & $\begin{array}{l}\text { GTM is based on deductive learning. It } \\
\text { gives grammar rules explicitly to } \\
\text { learners and the rules are reinforced } \\
\text { with examples (Larsen, 2000). }\end{array}$ & $\begin{array}{l}\text { writing } \\
\text { reading }\end{array}$ & $\begin{array}{lr}\text { translation, } & \text { reading } \\
\text { comprehension, } & \text { vocabulary } \\
\text { drills, sentence } & \text { completion, } \\
\text { and composition } & \\
\end{array}$ \\
\hline $\begin{array}{l}\text { Direct Method } \\
(\mathrm{DM}), 1890 \mathrm{~s}\end{array}$ & $\begin{array}{l}\mathrm{DM} \text { is based on inductive learning. } \\
\text { Learners are directly exposed to L } 2 \text {. }\end{array}$ & $\begin{array}{l}\text { speaking } \\
\text { listening }\end{array}$ & $\begin{array}{l}\text { conversation, vocabulary } \\
\text { drills, dictation for listening }\end{array}$ \\
\hline $\begin{array}{lr}\begin{array}{l}\text { Audio } \\
\text { Method }\end{array} & \begin{array}{l}\text { Lingual } \\
\text { 1960s }\end{array} \\
\end{array}$ & $\begin{array}{l}\text { ALM is based on behaviorism that } \\
\text { advocates learning a language through } \\
\text { habit formation with immediate result. }\end{array}$ & $\begin{array}{l}\text { listening } \\
\text { speaking }\end{array}$ & $\begin{array}{l}\text { memorizing, grammar games, } \\
\text { repetition, chain and } \\
\text { substitution drills }\end{array}$ \\
\hline $\begin{array}{l}\text { Community } \\
\text { Language } \\
\text { Learning (CLL) } \\
1970 \mathrm{~s}\end{array}$ & $\begin{array}{l}\text { CLL i } \\
\text { views } \\
\text { makes } \\
\text { their } \mathrm{f}\end{array}$ & $\begin{array}{l}\text { speaking } \\
\text { listening }\end{array}$ & $\begin{array}{l}\text { L1-L2 lexical translation, } \\
\text { experience sharing, reflective } \\
\text { listening, repetition drill, and } \\
\text { group task to know each other }\end{array}$ \\
\hline $\begin{array}{l}\text { Silent Way (SW) } \\
1970 \text { s }\end{array}$ & ion & & $\begin{array}{l}\text { e coding with colour } \\
\text { fidel charts }\end{array}$ \\
\hline $\begin{array}{l}\text { Suggestopedia } \\
1970 \mathrm{~s}\end{array}$ & ing & & $\begin{array}{l}\text { arning, concert, } \\
\text { etc. }\end{array}$ \\
\hline $\begin{array}{lr}\text { Total } & \text { Physical } \\
\text { Response } & \text { (TPR) } \\
1970 \mathrm{~s} & \end{array}$ & $\begin{array}{l}\text { TPR is based on Innate Bio-Program, } \\
\text { Brain Lateralisation, and } \\
\text { Stress-affective Filter to up effective } \\
\text { learning. }\end{array}$ & & $\begin{array}{l}\text { ids for action, role } \\
\text { and action sequence }\end{array}$ \\
\hline $\begin{array}{l}\text { Communicative } \\
\text { Approach } \quad \text { (CA) } \\
1970 \text { s }\end{array}$ & $\begin{array}{l}\text { ised on real communication. It } \\
\text { es function rather than form. }\end{array}$ & $\begin{array}{ll}\text { king } \\
\text { ning }\end{array}$ & $\begin{array}{l}\text { urse, role play, } \\
\text { es, picture strip } \\
\text { d sentences }\end{array}$ \\
\hline $\begin{array}{lr}\text { Audio } & \text { Visual } \\
\text { Method } & \text { (AVM) } \\
1970 \mathrm{~s} & \\
\end{array}$ & $\begin{array}{l}\text { y to teach less and } \\
\text { rates mastering of } \\
\text { elby, 2012). }\end{array}$ & list & $\begin{array}{l}\text { pronunciation and fluency } \\
\text { drills using audio, video, and } \\
\text { computerized lessons }\end{array}$ \\
\hline $\begin{array}{l}\text { Cooperative } \\
\text { Learning } \\
1970 \text { s }\end{array}$ & $\begin{array}{l}\text { CL is based on mutual cooperation of } \\
\text { the learners to maximize everyone's } \\
\text { learning to reach a common goal. }\end{array}$ & $\begin{array}{l}\text { speaking } \\
\text { reading } \\
\text { writing }\end{array}$ & $\begin{array}{l}\text { social and conflict-resolution } \\
\text { based interaction, think-pair- } \\
\text { share, and circle the sage }\end{array}$ \\
\hline
\end{tabular}




\begin{tabular}{|c|c|c|c|}
\hline $\begin{array}{l}\text { Presentation-Pract } \\
\text { ice-Production } \\
\text { (PPP) 1980s }\end{array}$ & $\begin{array}{l}\text { PPP is based on three principles: } \\
\text { Presentation, Practice, and Production. } \\
\text { Teachers present a phenomenon which } \\
\text { learners practice and produce finally. }\end{array}$ & $\begin{array}{l}\text { speaking } \\
\text { listening } \\
\text { reading } \\
\text { writing }\end{array}$ & $\begin{array}{l}\text { It follows almost all the } \\
\text { activities of TPR method. }\end{array}$ \\
\hline $\begin{array}{l}\text { Task-Based } \\
\text { Approach (TBA) } \\
\text { 1980s }\end{array}$ & $\begin{array}{l}\text { TBA theorizes that we learn a language } \\
\text { when we use it. So task is greater than } \\
\text { the language (Harmer, 2006). }\end{array}$ & $\begin{array}{l}\text { speaking } \\
\text { listening } \\
\text { writing }\end{array}$ & $\begin{array}{l}\text { completing a task in groups } \\
\text { and making it public, problem } \\
\text { solving activities }\end{array}$ \\
\hline $\begin{array}{l}\text { Multiple } \\
\text { Intelligences (MI) } \\
\text { 1980s }\end{array}$ & $\begin{array}{l}\text { It has } 8 \text { intelligences: linguistic, } \\
\text { logical, intrapersonal, kinesthetic, } \\
\text { interpersonal, naturalist, musical, and } \\
\text { spatial-visual. }\end{array}$ & $\begin{array}{l}\text { speaking } \\
\text { listening } \\
\text { reading }\end{array}$ & $\begin{array}{l}\text { MI activities conform to those } \\
\text { of CLT, TPR, ALM, AVM, and } \\
\text { Suggestoedia. }\end{array}$ \\
\hline $\begin{array}{l}\text { Natural Approach } \\
\text { (NA) } 1980 \mathrm{~s}\end{array}$ & $\begin{array}{l}\text { NA follows input hypothesis. Learners } \\
\text { are exposed to comprehensible input. }\end{array}$ & $\begin{array}{l}\text { speaking } \\
\text { listening }\end{array}$ & $\begin{array}{l}\text { situational dialogues using } \\
\text { chart, pictures, and other realia }\end{array}$ \\
\hline $\begin{array}{l}\text { Learner } \\
\text { Autonomy (LA) } \\
\text { 1990s }\end{array}$ & $\begin{array}{l}\text { LA is based on the "ability to take } \\
\text { charge of one's own learning" (Holec, } \\
\text { 1981). }\end{array}$ & $\begin{array}{l}\text { speaking } \\
\text { listening } \\
\text { writing }\end{array}$ & $\begin{array}{lr}\text { pair work, } & \text { crosswords, } \\
\text { audio-video } & \text { recordings, } \\
\text { grammar } & \text { games, } \\
\text { Computerized learning }\end{array}$ \\
\hline $\begin{array}{l}\text { Lexical Language } \\
\text { Learning (LLL) } \\
\text { 1990s }\end{array}$ & $\begin{array}{l}\text { LLL is based on learning language } \\
\text { through vocabulary in the form of } \\
\text { collocations, idioms, phrasal verbs, etc. }\end{array}$ & $\begin{array}{l}\text { speaking } \\
\text { writing }\end{array}$ & $\begin{array}{l}\text { word-clouds, vocabulary } \\
\text { drills, corpus study to know } \\
\text { and use most frequent words }\end{array}$ \\
\hline
\end{tabular}

\subsection{Methods of ELT Used in Ethiopia}

While observing the applications of ELT methods in the EFL classrooms, the participant-teachers were firstly asked as to their uses of ELT methods. There was a common answer that they follow learner-centred approach. Learner-centred approach, which is an offshoot of methods like Learner Autonomy and Multiple Intelligences, is not practiced in reality as the learners are fully dependent on the teachers for any activity and are reluctant to develop a sense of responsibility for the outcome of their learning. Viewing this paradoxical stance on using learner-centred approach, participant observation of 6 EFL classrooms and unstructured interview of 15 teachers were held to determine how and which ELT methods were being used with reference to 16 ELT methods. In this pursuit, two aspects were studied: application of method (AOM) and degree of application (DOA) by using Likert-type scale. AOM was ascribed two values $(+)$ and $(-)$, whereas DOA was ascribed six temporal values in descending degree: \{always, often, sometimes, seldom, rarely, and never $\}$. The first three temporal values: Always, Often, and Sometimes were assigned (+) to affirm the application of any method, whereas, Seldom, Rarely, and Never were assigned (-) to negate the application of any method regardless of their DOAs. In addition, an attribute 'Unfamiliar' was also added under DOA to bring out the teachers' unawareness of ELT method(s) as shown in table-3.

Table 3. Methods of ELT Used in Ethiopia

\begin{tabular}{llllll}
\hline Methods & DOA & AOM & Methods & DOA & AOM \\
\hline $\begin{array}{l}\text { 1. Grammar Translation } \\
\text { Method }\end{array}$ & Often & + & 9. Audio Visual Method & Rarely & + \\
\hline 2. Direct Method & Sometimes & + & 10. Cooperative Learning & Rarely & - \\
\hline 3. Audio Lingual Method & Sometimes & + & 11. PPP & Often & + \\
\hline $\begin{array}{l}\text { 4. Community Language } \\
\text { Learning }\end{array}$ & Rarely & - & 12. Task-Based Approach & Unfamiliar & - \\
\hline 5. Silent Way & Seldom & - & 13. Multiple Intelligences & Unfamiliar & - \\
\hline 6. Suggestopedia & Never & - & 14. Natural Approach & Unfamiliar & - \\
\hline 7. Total Physical Response & Sometimes & + & 15. Learner Autonomy & Rarely & - \\
\hline 8. Communicative Approach & Often & + & $\begin{array}{l}\text { 16. Lexical Language } \\
\text { Learning }\end{array}$ & Unfamiliar & - \\
\hline & & & & & \\
\hline
\end{tabular}

The results of DOA in table 3 show not only the absence of effective methods but also unfamiliarity with important methods like Natural Approach, PPP, and Lexical Language Learning among the teachers. The table also falsifies the claim of practicing learner centred approach because neither the teachers encourage the learners in a quest for self learning activities nor the course components favour autonomous learning. 


\subsection{Linguistic Impediments}

Using participant observation and unstructured interview, ten linguistic impediments were explored as follows.

\subsubsection{Faulty Methods}

Here, faulty methods have two connotations: (i) using wrong method(s) and (ii) using methods wrongly. 'Using wrong methods' implies here unawareness of using a particular ELT method for a particular level of learners, whereas 'using methods wrongly' refers to using a method aimlessly without knowing its effectiveness to improve a particular language skill, e.g. listening, speaking, reading, or writing. Unstructured interview and participant observation revealed that average teachers not only use wrong methods but also use them wrongly. None of the prescribed text-books heed to ensure the correlation between methods and their respective activities to groom different levels of learners to master a particular skill.

\subsubsection{Sloppy Curriculum}

The curriculum is sloppy for two reasons: (i) it lacks authentic and interactive lessons for real communication. Even if, the textbook contains some interactive lessons, there is no practice of the same as the teachers focus more on teaching grammar and vocabulary; (ii) the textbooks are frequently changed breaking the continuation and natural hierarchy of course components.

\subsubsection{English: A medium of Obstruction rather than Instruction}

Not to say of active participation in classroom activities, students are often deprived of understanding what they hear from their teachers or read in their textbooks (Bogale, 2009). English is ignored as a medium of instruction from grade1 to 8. English becomes medium of instruction from grade 9 onwards. English is ignored again in the diploma program especially in Oromia region. Students of this region complain of being dismissed from the university because of their incompetence in English. The students can express their subject-matter knowledge in L1 but not in English. Moreover, study materials are not easily available in English. Thus, English appears to be a medium of obstruction rather than instruction.

\subsubsection{Audio-Visual Teaching Reduced to Nil}

Though, most of the EFL institutions are equipped with language labs but there is no practical use of audio-visual aids or activities for the learners due to exceedingly large number of students and the teachers' technical inability to operate the lab. The learners remain deprived of mastering two main skills: speaking and listening for lack of audio-visual drills on phonological aspects of English language.

\subsubsection{Communicative Incompetence of the Teachers}

Here, communicative incompetence implies teachers' low proficiency in using the language. Average teachers lack particularly in areas like word stress, intonation, sentence formation, words choice, stylistic, and cultural nuances of English language.

\subsubsection{Pedagogic Incompetence of the Teachers}

The majority of teachers lack the essential subject matter knowledge to teach the learners of all levels. Many postgraduate students with poor proficiency in English are often assigned to teach undergraduate English courses. Such a practice of teaching by novice instructors may form a chain of incompetent teachers in Ethiopia.

\subsubsection{Exam Anxiety and Lack of Performance Based Assessment}

Normally, formative and summative assessments are held to assess learners' theoretical competence in grammar and vocabulary rather than practical performance or usage of the same. Such a mode of exam not only confines the learners to rote learning but also causes great anxiety of passing the test by memorizing, cheating, or pestering teachers. The present mode of exam neither measures the progression of learning nor explores learners' areas of weaknesses followed by suggestive feedbacks to overcome them.

\subsubsection{Lack of English Exposure outside Classroom}

There is hardly any exposure of practicing English outside classroom. The average Ethiopians believe that they can easily do away with English as English is not a crutch to survive in Ethiopian society. Amid 82 languages and several dialects, the Ethiopians communicate in their regional languages to establish their linguistic identities sidelining other languages including English.

\subsubsection{English: Taught as a Subject rather than a Language}

In present scenario, English is used merely as a subject for few months in schools or colleges where the learners' only worry is clearing English paper with pass grade rather than learning or mastering it innately. 


\subsubsection{Mother Tongue Obsession}

After the amendment in Ethiopian Constitution in 1994, each regional state was given a right to choose, use, and diffuse its languages from both educational and cultural perspectives. As a result, almost all the states showed their obsession towards mother tongue education which resulted into a trilingual education consisting of mother tongue + Amharic + English (Bogale, 2009). In this proliferation of mother-tongue education, the end users (students) have experienced more harm than good because mother tongues became the media of instruction as well as subjects from the $1^{\text {st }}$ to $8^{\text {th }}$ grade (Seidel, 2009). Such a proclivity of mother tongues in education does not orient the learners towards learning and mastering English.

\subsection{Non-Linguistic Impediments}

Seven non-linguistic impediments were found as multi-headed hydra as they are seemingly hard to be solved with a single effort due to their persistent and pervasive nature as follows.

\subsubsection{Time-Place-Manpower Constraints}

Time, place, and manpower (teachers) constraints are intertwined due to large number of students. According to international standard, the ideal number of students in an EFL classroom of $15 \times 20$ feet size is 15 to 30 students. According to Hayes (1997), the ideal number of students in language class is 30 at most, because only under such a scale can offer enough chances for the students to communicate with each other. If we maintain this size and number of students for closer attention, it requires more periods of teaching. More periods of teaching require more manpower which is not available especially in Haramaya and Dire Dawa University at present. If we increase the classroom size, the number of students will increase. If the number of students increases, teaching, learning, and overall interaction are affected adversely.

\subsubsection{Teachers' Comfort}

Most of the teachers show lackadaisical attitude in setting exam papers in case the students' number exceeds 100 as it requires more amount of time in correcting exam papers. For instance, writing-test and analytical (subjective) questions are totally excluded from the final exam papers and multiple choice questions are instead given as they are easier to be corrected by anyone in lesser amount of time with the help of answer-keys. Ironically, writing-test is often given as classroom activities to elapse the lecture duration; or as homework which is arguable whether the homework is done by the students or others. Besides, the students often complain of teachers' reluctance in correcting their faulty written composition.

\subsubsection{Ego War among Teachers}

The ego war mainly arises out of age supremacy, designation supremacy, knowledge supremacy, and mean intellectual jealousy among the teachers. Senior teachers show high-handedness towards juniors and juniors do not like to be influenced by the seniors. In many instances, an individual's constructive ideas on ELT matters are plagued by robust views of a group of underperforming teachers.

\subsubsection{Low Reward Causing Reluctance to Teach}

The teachers often feel that they are not well rewarded. This fact surfaced during unstructured interviews with some instructors when they said sarcastically that "If they are rewarded like their expatriate colleagues, they will teach 24 hours a day". Though this remark sounded a bit humorous but it had a tinge of dissatisfaction and outburst due to six times lower remuneration of the local teachers than their counterpart expatriate colleagues.

\subsubsection{Disrespect towards Teaching Profession}

Due to low remuneration, teaching is not preferred as a noble profession in Ethiopia. Teaching is taken as a last resort by many young English teachers. They are more ambitious of becoming merchants, medical professionals or engineers but not teachers.

\subsubsection{Alien Control of EFL Classroom}

Alien Control of EFL Classroom refers specifically to external control of the EFL classrooms by super-imposed committee. It was found in the secondary schools of Harari region that an external committee, which does not have any active role in teaching, controls and monopolizes the entire examination activities by setting question papers for both mid-term and final exams of grade 9 and 10. The concerned teachers are mum over the issue in the hope that Ministry of Education (MOE) will look into the matter some day and do the needful.

\subsubsection{Lack of Motivation and Professional Vision}

Lack of motivation was found in the participants' temperament as they feel that English can be used only within the four walls of classroom or in compelling situations. They are either ignorant of the importance of English or 
they willingly undermine the importance of English. Moreover, the prescribed curriculum lacks professional vision as it does not contain any segment on business communication to groom students to be an efficient communicator at workplace.

\subsection{Remedial Insight}

To overcome the aforementioned linguistic impediments, the present research proposes an empirical approach called Integrated Iconic Approach (IIA). IIA has been conceptualized under the umbrella concept of principled eclecticism proposed by Larsen (2000) which encourages learners to be autonomous in their learning by collective use of ELT methods. In IIA, integrated refers to integrating the effective essence of all ELT methods, whereas, iconic refers to learning supported by visuals as our brain is more receptive to visuals than text.

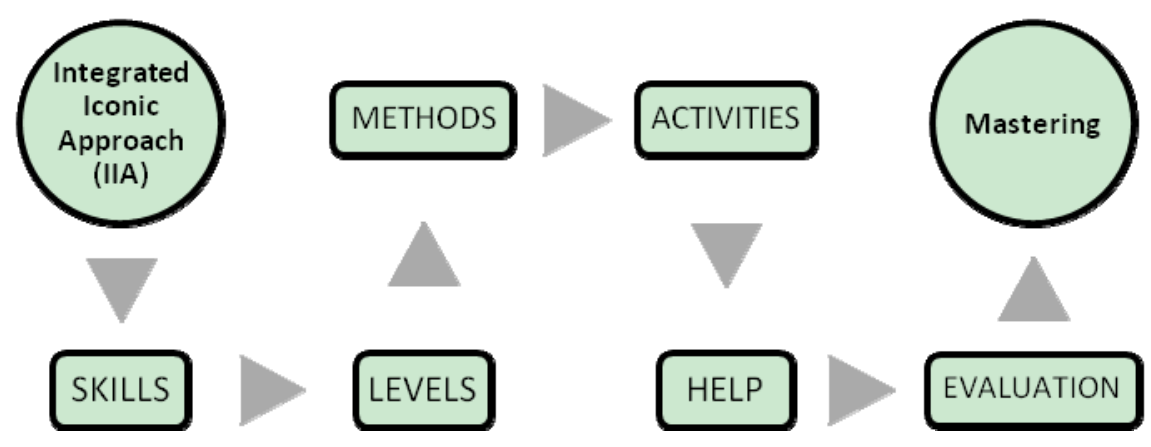

Figure 2. Conceptual Framework of IIA

The conceptual framework of IIA in figure 2 prescribes six sequential strategies namely skills, levels, methods, activities, help, and evaluation to reach the stage of mastering, whereas table 4 enlists the plausible components of the six strategies.

Table 4. Components of IIA

\begin{tabular}{|c|c|}
\hline STRATEGIES & COMPONENTS \\
\hline Skills & Listening $\rightarrow$ Speaking $\rightarrow$ Reading $\rightarrow$ Writing \\
\hline$\downarrow \rightarrow$ & $\begin{array}{l}\text { Pre-production, Early production, Speech emergence, Intermediate fluency, Advanced } \\
\text { Fluency }\end{array}$ \\
\hline$\stackrel{\downarrow}{\longrightarrow \text { Methods }}$ & $\begin{array}{l}\text { Grammar Translation Method (GTM), Total Physical Response (TPR), Communicative } \\
\text { Approach (CA), Community Language Learning (CLL), Cooperative Learning (CL), } \\
\text { Natural Approach (NA), Direct Method (DM), Multiple Intelligences (MI), Task-Based } \\
\text { Approach (TBA), Audio Lingual Method (ALM), Silent Way (SW), Learner } \\
\text { Autonomy (LA), Audio Visual Method (AVM), Suggestopedia (S), } \\
\text { Produce-Present-Practice (PPP), Lexical Language Learning (LLL) }\end{array}$ \\
\hline $\begin{array}{l}\downarrow \rightarrow \text { Activities } \\
\end{array}$ & $\begin{array}{l}\text { Independent Activities: (1) Vocabulary learning by listening Story, (2) Listening and } \\
\text { Watching Native Speakers' Interaction, (3) Opinion Gaps, (4) Jigsaw Task, (5) } \\
\text { Collocational and Contextual Vocabulary Drills, (6) Questions and answers, (7) } \\
\text { Commands, Comments, (8) Brainstorming, (9) Paraphrase, (10) Memorization, (11) } \\
\text { Inductive Grammar learning, (12) Peripheral Learning, (13) Scrambled sentences, (14) } \\
\text { Action Commands, (15) Dictation, (16) Fluency Drill (17) Paraphrasing, (18) Symbolic } \\
\text { learning, (19) Translation 'L1-L2/L2-L1', (20) Rhetoric and Idioms }\end{array}$ \\
\hline & $\begin{array}{l}\text { Interdependent Activities: (21) Role play: Teacher \& Student, or Student \& Student, or } \\
\text { Solo Interaction, (22) Group Discussion, (23) Public Speaking, (24) Composition, (25) } \\
\text { Purposive Writing, (26) Précis writing, (27) Review writing, (28) Thinking strategies, } \\
\text { (29) Discussion games, (30) Presentation, (31) Corpus Study (32) Discussion Games } \\
\text { (33) Language Games, (34) Think-Pair share }\end{array}$ \\
\hline Help & $\begin{array}{l}\text { Iconic Communicative Lexicon, Collocational Lexicon, Iconic Communicative } \\
\text { Structures, Pronunciation, Contrastive Referential Grammar, Rhetoric and Idioms }\end{array}$ \\
\hline$\downarrow \rightarrow$ & Unconscious Evaluation, Self Evaluation, and Conscious Evaluation \\
\hline
\end{tabular}


The following are the brief accounts of the strategies and their components. The downward and rightward arrows in table 4 imply the occurrence of strategies and their respective components one after another but not vice versa.

\subsubsection{Skills}

The first strategy of IIA is to decide 'skill to be learnt'. Though, the plausible sequence of language skills begins with two audio-lingual skills: Listening and Speaking followed by two graphic skills: Reading and Writing, but a learner may decide to learn and master any skill based on his/her needs.

\subsubsection{Levels of Learners}

In line with the selected skill, IIA's next strategy is to measure and decide levels of learners. Considering the varied degrees of linguistic proficiency, the learners are labeled with levels like beginner, pre-elementary, elementary, upper-elementary, pre-intermediate, intermediate, upper-intermediate, advanced, very advanced, and finally proficiency level in which learners master an L2 with precision sometimes superior to that of some native speakers. As for measuring the levels of learners, there are several online and offline level-tests. For instance, one can use the following links to design a level-test to measure the levels of learners.

http://www.esl-lounge.com/student/level-test.php

http://www.dllr.maryland.gov/gedmd/cs/eslcslevel.pdf

http://www.englishclub.com/esl-exams/levels-test-wc-start.htm?

As a part of IIA, learners are categorized into five levels based on the classification made by Krashen \& Terrell (1983) as follows.

Level- 1: Pre-Production (PP)

PP level spans from 0-6 months in which learners with their minimal comprehension do not actually produce language rather listen attentively and keep parroting. Learners, at this level, know up to 500 words and communicate with 'yes/no' cues. Teachers should normally use TPR method for PP level learners.

\section{Level-2: Early Production (EP)}

EP level spans from six months to one year and the learners know active vocabulary of about 1000 words. This is the phase of item learning, i.e. learning language at word and phrase level. The learners are involved in interactive activities that require one word answer and response.

\section{Level-3: Speech Emergence (SE)}

SE level spans from one to three years in which learners acquire a vocabulary of about 3,000 words and communicate with simple phrases and sentences that may or may not be grammatically correct. Teachers are supposed to (i) ask questions that require short answers, (ii) involve learners in explaining phenomena in terms of 'why' and 'how', and (iii) give activities like listening story, reading short essays, understanding-answering questions about charts and graphs, matching and defining words, pair work, and sharing life experience, etc.

Level-4: Intermediate Fluency (IF)

This level spans from three to five years in which learners acquire a vocabulary of about 6000 active words. They start using more complex sentences in speaking and writing with few grammatical errors. The learners are expected to synthesize what they have learned and analyze more complex concepts.

\section{Level-5: Advanced Fluency (AF)}

To reach AF level, learners normally take six to ten years in which their limit of vocabulary exceeds 6000 communicative words and they acquire outstanding academic language proficiency. The AF learners are supposed to have utmost proficiency in L2 phonology, morphology, syntax, semantics, and discourse. Learners are trained in higher activities like, public speaking, delivering rational talk, storytelling, compiling and presenting views of distinguished speakers and writers, practical teaching, literary composition, etc. to have native-like or superior-to-native proficiency.

Thus, levels of learners play a decisive role in IIA framework as any further decision of applying methods and activities is taken in accordance with the levels of learners. After deciding the levels of learners, IIA decides effective ELT methods.

\subsubsection{Methods}

Since one ELT method is not enough to master a particular language skill, IIA decides and employs effective ELT 
methods for the pre-selected skill and the level of learners in an integrated and sequential manner. For instance, an EP level learner should be first exposed to an ELT method like TPR followed by NA, DM, and CM respectively.

\subsubsection{Activities}

After deciding methods, IIA decides effective ELT activities of the selected methods for the pre-selected skill and the level of learners. In table 4, the rightward arrow used in the activities box implies that simple activities should be followed by complex ones. It is imperative to add that 34 activities listed in table 4 have been sensibly arranged to arouse and uphold the interest of learners which eventually leads to and aims at bringing out optimum mastery in L2.

\subsubsection{Help}

The next strategy in IIA is to access a Help Database comprising six types of linguistic help to strengthen the process of mastering as follows.

\section{A. Iconic Communicative Lexicon}

EFL Learners are often obsessed with a misconception that more words they know better they can speak English. A research in lexicography has shown that a person, who is well proficient in speaking or writing English, knows around five to six thousand words (Kucera, 1993). These five to six thousand words are called communicative or common words which have been extracted from the spoken and written corpus based on their higher frequency of occurrence especially in spoken communication. The quest for communicative words in English is not a new phenomenon. A host of language scholars like (Ogden, 1930), West (1953), Hindmarsh (1980), Carter (1987), and McCarthy \& O'Dell (1999) vested their interest in formulating communicative words. In this regard, IIA proposes the database of 5000 communicative words in iconic (photo/video) forms. One of the best examples of an iconic lexicon can be seen as Longman Wordwise Dictionary published by Longman Press.

\section{B. Collocational Lexicon (CL)}

A word acquires its meaning or word-class only when it occurs in association or collocation with other words. A collocation is a group of words that are often used together (McCarthy \& O'Dell, 2005). For example, in a collocational phrase like take a photo, no word other than photo collocates with take to give the same meaning. Similarly, in a phrase like strictly prohibited, the word prohibited is naturally preceded by an adverb like strictly. English words are highly polysemous; for instance, American Heritage Dictionary ( ${ }^{\text {rd }}$ Ed.) gives 40 different meanings of "set" which make the learners fumble in deciphering the intended meaning of the word as they usually pick up the first meaning. Similarly, a word is used as different word classes. For example, a traditional lexicon may list up a word like "back" with different word-classes, e.g. noun, verb, adjective, and adverb as in tanned back, back a car, back door, and turn back respectively. But a novice learner picks up the very first meaning with first word-class which often fetches an unintended meaning.

To meet such lexical issues, IIA proposes a collocational lexicon that resolves the right meaning, word-class, and usage of a word in phrasal, syntactic, and discourse forms. For a given word, the proposed CL gives first phrasal collocation. Thereafter, the phrasal collocation is exemplified and contextualized in sentence and discourse forms to resolve the right meaning, word-class, and usage of the word. Today, collocational approach is reputedly the best approach to learn and master vocabulary. Hoge (2012), one of the leading English trainers, is a great advocator of collocational approach in his English teaching program Effortless English. For him, phrase is the first unit of language to be taught and learnt. People learning foreign languages tend to learn quicker by remembering collocational phrases more so than individual words.

\section{Iconic Communicative structures}

The help database of iconic communicative structures is supposed to have visual elucidation of around 123 English structures (sentence patterns) which suffice to construct almost all types of sentences in English with slight permutation. Iconic or visual elucidation of sentence makes sentence learning easier, faster, and more vivid. The URL www.englishclass101.com/video provides good examples of iconic syntax.

\section{Pronunciation}

The help database of pronunciation helps the learners on phonological aspects. IIA expects the learners to master 60 essential rules of stress and intonation given by Allen (1965). 


\section{E. Contrastive Transfer Grammar (CTG)}

The purpose of CTG is to equip learners with equal communicative competence in L1 and L2. CTG gives a quick understanding of transferring L1 syntax into L2 with its contrastive knowledge base of L1 and L2 syntactic structures. In IIA framework, CTG is envisaged to have a contrastive database not only of L1 and L2 syntactic structures but also phonological, morphological, and semantic structure based on the pattern of English-Hindi Transfer Grammar written by Surajbhan Singh (2003).

F. Rhetoric and Idioms

This database elucidates 65 rhetorical devices and 240 current idioms to help IF and AF level learners master figurative systems and stylistic nuances of English language.

\subsubsection{Evaluation}

Normally, any method of teaching does not hold any value if it is not followed by an evaluation. Though, the term evaluation is often associated with assessment and test and sometimes interchanged erroneously, but it is useful to think of them as separate but connected ideas and processes (Djihadi, 2010). Burhan (2009) and Kizlik (2012) also distinguish these three overlapping concepts. Evaluation is used in broader perspective subsuming both assessment and test, whereas assessment is being widely used in the field of ELT with two basic types: formative and summative. Test is the narrowest in its scope as it is a special form of assessment. Critically speaking, the learners feel over-assessed and over-stressed due to formative assessment, whereas, summative assessment mounts up more pressure on the learners as it becomes vital for them to get through the test with good grades.

IIA prefers the use of the term evaluation due to its wider concern to measure the progression of learning and mastering by fully discarding summative assessment and partially incorporating formative assessment. As a part of evaluation, IIA proposes Unconscious Evaluation, Self Evaluation, and Conscious Evaluation. Unconscious evaluation is specifically suggested for $P P$ and $E P$ levels' learners as shown in figure 4 . It aims to lower anxiety and over-consciousness of learners as learning goes down if the anxiety is higher (Krashen, 1987). Self evaluation enables learners to test and correct themselves using computerized online/offline tests mainly to avoid any embarrassment arising out of poor scores or grades in the presence of peers and teachers. Conscious evaluation is made for IF and AF levels' learners to measure the performance (usage) rather than competence (knowledge) of the language. Performance-based assessment "represents a set of strategies for the application of knowledge, skills, and work habits through the performance of tasks that are meaningful and engaging to students" (Hibbard, 1996). Conscious evaluation intends to ensure learners' mastery in English phonology, morphology, syntax, semantics, pragmatics, and stylistics. If the performance is unsatisfactory, learners are advised to backtrack, work out, and make up for the shortcomings till the mastery reaches the optimum level. Thus, the purpose of proposing these three forms of evaluation is to make learners feel at ease in course of mastering the language.

\subsubsection{Strategic Processing of IIA}

The following flow chart (figure 4) is the rendition of strategic processing of the aforementioned six strategies. It is noteworthy that the processing has been epitomised with respect to speaking skill of $E P$ level learners only. The question marks (? ? ? ? ?) used in level, activity, and method boxes imply that these strategies have not been resolved, whereas rightward arrow indicates the selection of methods and activities based on their increasing degrees of ease and effectiveness. 


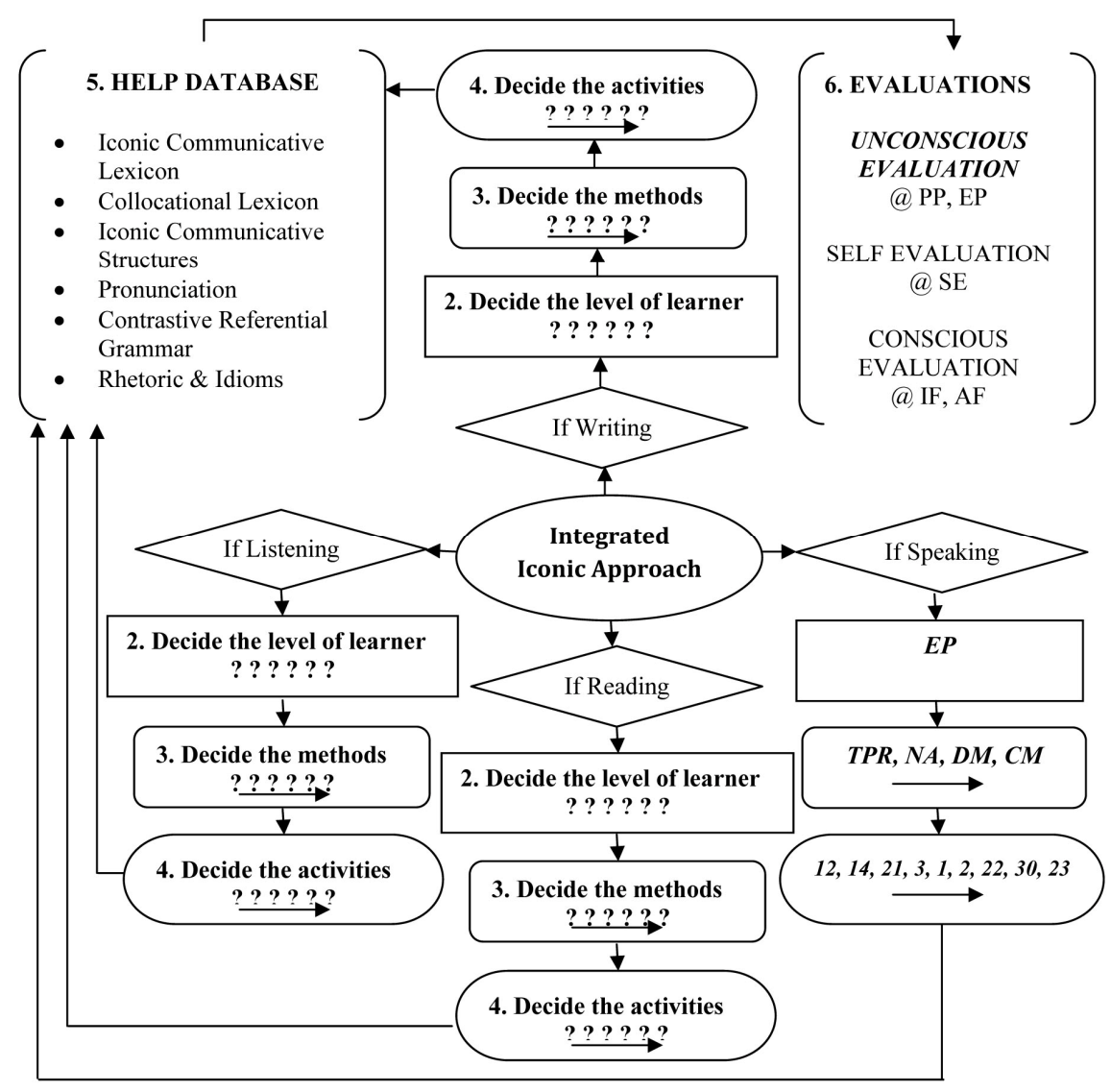

Figure 4. Strategic Processing of IIA

The flow-chart shows that if speaking skill (as shown in the diamond box) is selected as the first strategy; the second strategy is to decide the level of learners. To typify, EP level (as shown in the rectangular box) has been chosen. The third strategy is to decide effective methods for the speaking skill of EP level learners. To typify, methods like TPR, NA, DM, and CM (as shown in the round rectangular box) have been chosen based on their increasing degree of ease and effectiveness. The fourth strategy is to decide effective activities of the selected methods. To typify, nine sequential activities: $12,14,21,3,1,2,22,30$, and 23 (as shown in the terminator box) have been chosen from table 4 based on their increasing degree of ease and effectiveness. The fifth strategy is to access help database which provides essential knowledge base to overcome any linguistic hurdles in the process of mastering English. The last strategy is evaluation in which learners are supposed to undergo three layered evaluation: unconscious, self, and conscious evaluation to ensure whether learning in conjunction with mastering is taking place expectantly or not. For EP level learners, unconscious evaluation has been selected as italicized in figure 4. In due course, the flow-chart is supposed to be used for developing a computerized interface by which a learner of different levels could be self guided for learning and mastering English language.

\section{Conclusion}

In its heuristic efforts, the paper has tried to attain its three objectives by exploring (i) the major ELT methods used globally and their varied degrees of application in the Ethiopian EFL classrooms, (ii) linguistic and non-linguistic impediments in mastering English, (iii) an empirical Integrated Iconic Approach to overcome linguistic impediments. To summarize the findings, six critical facts are apt to be reiterated here. Firstly, the Ethiopian teachers do not keep abreast of ongoing ELT activities of worldwide significance. Secondly, English is being taught and learnt as a subject rather than as a language because English is exposed to the learners only within the four walls of classroom as a part of sloppy curriculum. It is forgotten that language is formed and moulded by the unconscious action of the community as a whole rather than compressing the grammar of a language into a set of rigid rules and stuffing them into the heads of the students. Thirdly, the course duration comes to an end by the time mastering phase begins. Fourthly, mother tongue education is emerging as a serious hindrance in English 
education. Fifthly, neither students nor teachers are motivated to excel in terms of mastering the language due to many-headed hydra like low reward causing reluctance to teach, mother tongue obsession, teacher's comfort, ego war among teachers, etc. Sixthly, the average teachers are not well-grounded in ELT because they themselves are products of weak TEFL programmes in the country. Thus, the need arises (i) to look into the existing linguistic and non-linguistic impediments from wider perspective; (ii) to diagnose further pertinent issues involving psycholinguistic, sociolinguistic, cultural, and political tinge; and (iii) to find holistic and lasting solutions of the non-linguistic impediments at the earliest. To overcome the aforementioned impediments under 3.1.1 and 3.1.2, the paper, finally, recommends both linguistic and non-linguistic measures to upgrade the overall quality of English Education in Eastern Ethiopia.

\subsection{Linguistic Recommendations}

A. Viewing the first linguistic impediment (faulty methods), the teachers need to have a special knack of using different ELT methods and activities for different levels of learners.

B. An immediate need is to prepare and make the six help database practically available for the learners' use.

C. Viewing the lack of authenticity and informativity in the current teaching materials like College English, Basic Writing Skill, etc., an immediate need is to replace them by authentic materials like Situational Dialogues, True Colors, Headway, etc. to expedite the mastering of English.

D. To fill the communicative and pedagogic lacuna, biannual TESOL workshops conforming to international standard need to be held for the existing and would-be English teachers.

E. A teacher without certification in Applied Linguistics, TEFL, TESOL, or ELT should not be assigned to teach English language. A stringent pedagogic test should be made compulsory for all the teachers to ensure whether they are competent enough to teach all levels of learners (PP, EP, SP, IF, and AF) or not.

F. Believing in the Input Hypothesis, the learners should be exposed to maximum comprehensible inputs like

(i) Watching TV cartoon programs like Barney, Mickey Mouse Club House, Sesame Street, etc. as they are not only fun-packed but highly educational to learn English in iconic forms,

(ii) Watching English movies, TV serials, Talk Shows like "Larry King Live" on CNN, "Hard Talk" on $B B C$, documentary channels like Discovery, National Geographic, The History, etc.,

(iii) Listening radio programs like BBC, Voice of America, podcasts, etc.,

(iv) Reading English story books, newspapers, magazines, etc.,

(v) Talking to or chatting with natives on social media.

G. In today's dot com world, iconic learning has become very easy. So one should make best use of the following resources as they embellish and expedite our learning process.

\section{Online Resources}

1. www.englishclass101.com/video

2. www.letstalk.co.in

3. www.dreamenglish.com

4. www.eslclub.com

5. watchenglish on www.youtube.com/user/atsusana69

\section{Offline Resources}
1. Face to Face
2. Headway
3. Cutting Edge
4. Easy English

5. Soft copy of Longman Wordwise dictionary

H. One should also use audio resources available on www.effortlessenglish.com, Longman's situational dialogues (Track 1-44), and Linguaphone to master real communication.

I. A language is better learnt by getting immersed in the speech community of that language, so the need arises to start English Immersion Programs and have more and more English community clubs so that the learners could know and use real communication.

J. Both the teachers and the learners should be given a chance of assimilating with the natives either by sending them to the English speaking countries as a part of Summer Immersion Abroad Programs for a considerable period of time or by inviting the natives to the local ghetto.

$\mathrm{K}$. To avail iconic learning, use www.youtube.com that is uploaded regularly with a host of interesting video lessons. 
L. Since test is an annoying factor in learning and mastering a language, English should be taught more as a language rather than as a subject. For this, the existing summative and competence-based test should be replaced by performance-based continuous assessment involving analytical and interactive exercises not only to measure the pace and outcome of learning but more importantly to expedite the mastering process. The goal of ELT is to make learners learn and master the language rather than forcing them to rote learning to merely clear English test paper.

M. English must be used as a medium of instruction right from nursery grade. The early introduction of English is crucial as one's memory and motor skills, i.e. 'the agility of speech organs to produce speech sounds' are very high at an early stage (Steinberg, 2001).

\subsection{Non-Linguistic Recommendations}

A. Make an amendment in language policy. Ethiopia is currently practicing the trilingual Education, which comprises 'mother tongue+Amharic+English'. To meet the present needs, this trend ought to be reversed, as 'English + Amharic + mother tongue'.

B. Eradicate Academic Poverty. It is awful to mention that one textbook is shared by two or three undergraduate students in Haramaya University. The students cannot afford to have even a pocket dictionary.

C. Let the sense of professionalism prevail to overcome the non-linguistic impediments like 4.4.3, 4.4.5, 4.4.6, and 4.4.7.

D. Since real quality education is transmitted to child right in the womb of the mother according to eugenics, women should be given the first priority of education as educated mothers can most effectively diffuse the knowledge to their offspring.

To sum up, mastering English is not a far-fetched goal; it is very much within our reach provided we transform all the aforementioned strategies and germane ideas into actions with an eagerness to excel consistently. The Ethiopians have immense potential to master English if they treat it like their mother tongues and make it their lifestyle.

\section{Acknowledgement}

The author extends his sincere thanks to Jeylan Woliye (Former Dean of SSSH, Haramaya University) for supplying relevant literature; Gonder University, Dire Dawa University, Alpha University for their substantial support to strengthen this research and all the esteemed Ethiopian colleagues and students for their insightful feedback.

\section{References}

Allen, W. S. (1965). Living English Speech: Stress and Intonation Practice for the Foreign Student. London: Longmans, Green.

Bloor, M., \& Wood, F. (2006). Keywords in Qualitative Methods. London: Sage Publications.

Bogale, B. (2009). Language Determination in Ethiopia: What Medium of Instruction? Proceedings Paper: 16th International Conference of Ethiopian Studies, Trondheim 2-7 July 2007.

Burhan, A. (2009). Second Language Teaching and Linguistics. Palembag: Grafika Telindo Press.

Carter. R. (1987). Is there a core vocabulary? Applied Linguistics, 8(2), 178-93. http://dx.doi.org/10.1093/applin/8.2.178

Djihadi, A. (2010). The Assessment in English Language Teaching: From Theory to Practice. Retrieved Nov. 29, 2012, from http://www.teachingenglish.org.uk/think/articles/testing-assessment

Eshetie, A. (2010). Language Policies and the Role of English in Ethiopia. Retrieved Nov. 29, 2012, from http://www.besig.org/Libraries/Bielefeld_Docs/Roles_of_English_and_language_policies_in_Ethiopia.sflb. ashx

Harmer, J. (2006). How to Teach English. New Delhi. Pearson Longman Press.

Hayes, U. (1997). Helping teachers to cope with large classes. ELT Journal, S(1), 31-38. http://dx.doi.org/10.1093/elt/51.2.106

Hibbard, K. M., \& Others. (1996). A teacher's guide to performance-based learning and assessment.

Hoge, J. A. (2008). Effortless English. Retrieved Dec. 06, 2012, from www.effortlessenglishclub.com

Hindmarsh, R. (1980). Cambridge English Lexicon. Cambridge. Cambridge University Press. 
Holec, H. (1981). Autonomy in Foreign Language Learning. Oxford: Pergamon.

Jeylan, W. (2010). English supremacy in Ethiopia- autoethnographic reflections. In Kathleen, \& Tove (Eds.), Multilingual Education Works. New Delhi. Orient Black Swan.

Kizlik, B. (2012). Measurement, Assessment, and Evaluation in Education. Retrieved Dec. 24, 2012, from http://www.adprima.com/measurement.htm

Krashen, S. (1987). Principles and Practice in Second Language Acquisition. Prentice-Hall International.

Krashen, S., \& Terrel, D. (1983). The Natural Approach: Language acquisition in the classroom. New York: Pergamon Press.

Kucera, H. (1992). The Mathematics of Language (American Heritage Dictionary). Boston: Houghton Mifflin.

Larsen-Freeman, D. (2000). Techniques and Principles in Language Teaching. Hong Kong: Oxford Uni. Press.

McCarthy, M., \& O’Dell, F. (1999). English Vocabulary in English. Cambridge: Cambridge University Press.

McCarthy, M., \& O’Dell, F. (2005). English Collocations in English. Cambridge: Cambridge University Press.

McKay, S. (2008). Researching Second Language Classrooms. New Jersy. LEA Publishers.

Ogden, C. (1930). Basic English: A General Introduction. London: Kegan Paul, Trench and Trubner.

Seidel, K. (2009). Changes in Ethiopia's Language and Education Policy -Pioneering Reforms? Proceedings Paper: 16th International Conference of Ethiopian Studies, Trondheim 2-7 July 2007.

Shelby, M. (2012). How to Master English. Retrieved Dec. 06, 2012, from http://esl.about.com/od/grammarguides/a/How-To-Master-English-Grammar.htm

Singh, S. (2003). English-Hindi Translation Grammar. Prabhat Prakashan Delhi.

Steinberg, D. (2001). Psycholinguistics: Language, Mind and World. London: Longman.

West, M. (1953). A general Service List of English Words. London: Longman. 